RU Экспериментальный анализ эффективности деловой игры и метода кейс-стади по сравнению с традиционными методами обучения в неязыковом вузе

\author{
Лысенко Н. Е.
}

Аннотация. Целью исследования является измерение эффективности инновационных и традиционных методов обучения иностранному языку, таких как кейс-стади, деловая игра и пересказ, для формирования профессиональных компетенций студентов в неязыковом вузе. В статье определены недостатки и преимущества методов кейс-стади, деловой игры и пересказа на основе наблюдения, анкетирования и контроля знаний студентов. Научная новизна работы обусловлена результатами проведенного количественного исследования, свидетельствующими об эффективности применения метода кейс-стади и деловой игры в сочетании с пересказом, в том числе при онлайн-обучении. В результате исследования выявлена эффективность применения метода кейс-стади и деловой игры в сочетании с адресованным пересказом и разработаны методические рекомендации для проведения занятий.

\title{
Experimental Research on Efficiency of Business Game and Case Study in Comparison with Traditional Teaching Methods at Non-Linguistic Higher School
}

Lysenko N. E.

\begin{abstract}
The paper aims to evaluate efficiency of innovative and traditional methods of foreign language teaching (case study, business game, rendering) when forming non-linguistic students' professional competences. Relying on pedagogical observations, students' survey results and analysis of their academic achievements, the author identifies advantages and shortcomings of case study, business game and rendering. Scientific originality of the paper is conditioned by the fact that relying on the quantitative research results, the author justifies efficiency of comprehensive application of case study, business game and listeneroriented rendering, both in full-time and distance teaching. The research findings are as follows: the author substantiates efficiency of comprehensive application of case study, business game and listener-oriented rendering, proposes methodological recommendations to organize educational process.
\end{abstract}

\section{Введение}

Использование инновационных методов обучения является актуальной задачей современного образования. Считается, что инновационные методы обучения, такие как кейс-стади и деловые игры, имеют преимущество по сравнению с традиционными методами обучения, так как предполагают большую эмоциональную и интеллектуальную вовлеченность обучающихся в решение поставленной задачи $[1 ; 7 ; 9 ; 11 ; 12]$. В то же время практика показывает, что при использовании кейс-стади и деловой игры на занятии по деловому иностранному языку в неязыковом вузе возникает много методических вопросов, требующих решения. Преподавателю необходимо учитывать такие факторы, как численность и неоднородность языковой подготовки студентов, подготовленность студентов не только по иностранному языку, но и по спецпредмету, содержание и направленность кейса и деловой игры. Некоторые методисты считают, что при использовании кейсов и деловых игр творческая составляющая заменяется обычным пересказом текста, подготовка к таким занятиям требует много времени и усилий, и наоборот, традиционные методы обучения, такие как пересказ, имеют преимущество при развитии умений организации содержания и языкового оформления повествования [2; 4].

Научная статья (original research article) | https://doi.org/10.30853/ped200134

(c) 2020 Авторы. ООО Издательство «Грамота» (๔ 2020 The Authors. GRAMOTA Publishers). Открытый доступ предоставляется на условиях лицензии СС BY 4.0 (open access article under the CC BY 4.0 license): https://creativecommons.org/licenses/by/4.0/ 
Так, при использовании методов кейс-стади и деловой игры и у обучаемых, и у преподавателей могут возникать такие трудности, как [1; 9]:

- трудность в преподнесении большого количества материала на занятиях;

- активное обучение требует слишком много времени для подготовки занятия;

- представляется невозможным использование активных методов обучения в многочисленной аудитории;

- возможность негативных последствий: отношение коллег и учащихся к новым подходам.

С точки зрения Т. Р. Богиевой, «было бы неправильно броситься от одной крайности в другую и отказаться от всех старых методик: надо бережно отобрать все лучшее, полезное, прошедшее проверку практикой преподавания» [1, с. 140]. Для этого были поставлены следующие задачи:

- изучить и проанализировать активность студентов при выполнении заданий с использованием методов кейс-стади, деловой игры и пересказа;

- определить эффективность применения метода кейс-стади и деловой игры в сочетании с пересказом, в том числе при онлайн-обучении;

- разработать методические рекомендации.

Были использованы такие методы исследования, как анализ и синтез научной, учебной и методической литературы по проблеме исследования, психолого-педагогический метод, включающий наблюдение за процессом обучения, анкетирование, письменный опрос, и статистический метод.

Теоретической базой исследования являются научные труды отечественных и зарубежных лингвистов Д. Котона, Д. Фолвея, С. Кента [11], О. Л. Чулановой, М. М. Мухамедовой [9], 3. В. Маньковской [8], А. Н. Войтковой, Т. В. Гончаровой [2], В. А. Шляховой, О. Н. Герасиной, Ю. А. Герасина [10] и др.

Практическая значимость исследования заключается в том, что описываемые в статье методические рекомендации могут успешно применяться в вузе неязыковой направленности в рамках освоения студентами иностранного языка как части будущей профессии, а также помогут преподавателю делового иностранного языка определить оптимальное сочетание инновационных и традиционных методов обучения.

\section{Основная часть}

Изучение научных источников по теме исследования позволяет нам констатировать, что в зарубежных профессионально направленных учебниках [11] умения пересказа развиваются при ответах на вопросы к тексту (Discussion), обсуждении в парах (Work in pairs). Кейс-стади или ролевая игра проводятся по окончании изучения раздела (Unit). Каждый кейс заканчивается письменной работой, например написанием электронного письма. В отечественных учебниках умения пересказа развиваются при ответе на вопросы по тексту, а затем эти вопросы могут использоваться в качестве плана для пересказа [10, с. 69]. С точки зрения А. Н. Войтковой и Т. В. Гончаровой, «обучение пересказу остается актуальным, так как подавляющая часть речевой деятельности в процессе овладения иностранным языком строится на основе иноязычного текстаобразца» [2, с. 316]. Адресованный пересказ, например пересказ группе студентов, позволяет развивать умения публичной речи, так как при пересказе используются речевые клише для вступления, основной части, заключения. Пересказ также позволяет диалогизировать общение посредством вопросов преподавателя к студенту и студента к аудитории.

На практическом занятии в контрольной группе пересказу предшествовало выполнение предтекстовых и послетекстовых заданий. Затем проводился опрос по тематической лексике, и далее студенты выполняли адресованный пересказ спецтекста группе в форме мини-лекции. С нашей точки зрения, пересказ в таком формате развивает операции анализа и синтеза, умения выбирать главное. Так, при адресованном пересказе студенты обращали внимание не только на использование лексики, но и на интонацию, задавали риторические вопросы с целью привлечения внимания аудитории, использовали знания по спецпредмету. Выступление проходило перед группой за кафедрой, что позволяло воспроизвести учебную ситуацию лекции. Пересказ спецтекста в форме «мини-лекции» для одногруппников позволяет преподавателю проконтролировать знание материала в занимательной для студентов форме и опросить каждого. Конкурс на лучшего лектора, выбираемого группой, повышал дух соревновательности. Таким образом, задание вызвало положительный отклик у студентов. Следует отметить, что такие задания эффективны в небольших группах из-за ограниченности по времени. К «минусам» адресованного пересказа относится повторяемость спецтекста, но монотонности удается избежать за счет авторской манеры пересказа и соревновательной направленности. Таким образом, можно рекомендовать адресованный пересказ для контроля знаний содержания спецтекста и развития умений выступать публично.

В экспериментальной группе проводились одна деловая игра и одно задание типа кейс-стади в течение семестра. С нашей точки зрения, в условиях высокой численности группы и большого объёма учебного материала целесообразно проводить одно занятие по методу кейс-стади и одну деловую игру, так как требуется много времени для подготовки и проведения. Деловая игра - это моделирование процессов и механизмов принятия решений с использованием различных моделей и групповой работы. Игра не ограничивается решением одной задачи, а требует «цепочки решений». Деловая игра по маркетингу проводилась со студентами 1-3 курсов. Подготовка к деловой игре включала перевод и распределение ролей, составление словаря, 
повторение речевых клише, по желанию подготовку видеопрезентации к роли. После ознакомления с деятельностью фирмы каждый из студентов предлагал свои варианты усовершенствования продукта с целью повышения продаж, использовались аудио- и видеоматериалы, подготовленные студентами. Два спикера из группы управляли ходом дискуссии, предоставляли слово выступающим и делали выводы. Следует отметить положительный отклик со стороны студентов при проведении деловой игры, активны были даже слабые по успеваемости студенты. В качестве недостатка можно назвать чтение своей роли с листа вместо устного выступления некоторыми студентами. Деловая игра требует значительных затрат по времени как для студентов, так и для преподавателя. Пример отрывка сценария проведенной ролевой игры [8, с. 35-40]:

"A Meeting: Widening the Market Share":

You are in the office of Heelys, Inc., Texas. The Company produces wheel roller trainers called Heelys. The Management convenes a meeting to improve the product. Each of you will play the roles described below. Use the information and language patterns from the exercises above.

- Chairperson of the meeting. Your task is to think up the agenda of the meeting. You must encourage participants to speak and make suggestions. Summarize the new ideas and make participants vote for the new one. - Secretary. Write a memo about the meeting, take the minutes of the meeting. - Participant 1. You suggest making the design of roller trainers suitable for young children...

Кейс-стади представляет собой сжатую во времени деловую игру. Кейс-стади (Case study) - система обучения, базирующаяся на анализе, решении и обсуждении реальных и смоделированных ситуаций, рассматривает конкретные случаи из деловой практики. Задача кейс-стади - обеспечить студента информацией, которая подтолкнет его к правильному ответу. Специфика кейсового обучения состоит в том, что одна и та же ситуация может иметь несколько решений. Этот метод изучения экономики был предложен в Гарвардском университете. Так, преподаватели этого университета считают оптимальным использование 4 кейсов в течение учебного года. В качестве новых форм кейсов для самостоятельного изучения следует отметить аудиоподкасты на сайте Гарвардского университета [12], который по факту представляет беседу ведущего с гостем, например ведущий Брайан Кенни и гость, профессор Гарвардской школы бизнеса, обсуждают кейс о том, как создать глобальную команду: “Today we’ll hear from Professor Neely about her case entitled Building a global team”. Послетекстовые задания в подкастах отсутствуют. Для того чтобы выбрать интересные и посильные студентам кейсы, следует учитывать их классификацию: 1) по размеру (мини-кейсы, ситуативные задания и др.); 2) по структуре представления учебного материала: структурированные, содержат правильные ответы; неструктурированные, не существует единого правильного варианта ответа; 3) по формам работы с текстом (кейсы со ссылками, графиками, с элементами двуязычного перевода, аудио-, видеокейсы). Для студентов экспериментальной группы выбрали мини-кейс с элементами двуязычного перевода по теме “Economic systems”. Выбор был обусловлен низкой терминологизированностью кейса, а также тем фактом, что тематика изучалась студентами на лекциях по спецпредметам.

В качестве самостоятельной работы студенты выполняли перевод дома. В условиях карантина кейс проводился онлайн с использованием программы «Скайп для бизнеса». К недостаткам проведения кейса онлайн следует отнести ограниченные возможности использования видео и презентаций из-за длительной загрузки, а также то, что некоторые студенты не включают камеру. Пример проведенного кейса [3, с. 4-6]:

Situation 1: Nigeria. The World Economic Forum on Africa. Imagine you are... an internship volunteer working here. High school students are vague about existing economic systems. You are expected to clarify... Task 1 Translate into English. Q: The term "mixed economy" is on the lips. What does it imply? Could you explain to us, pls? A: «Смешанная экономика» комбинирует элементы «рыночной экономики» и «командной». Она имеет частный сектор и государственный. Task 1.2 Now you are on your own. Display your initiative - more questions could be asked and more answers - given.

После деловой игры и кейс-стади проводилось анкетирование студентов по теме «Преимущества и недостатки деловой игры и кейс-стади», результаты которого представлены на Рисунках 1, 2. К основным преимуществам использования метода кейс-стади и деловой игры можно отнести то, что задействованы творческие способности студентов при составлении собственного текста выступления, нет возможности механически пользоваться переводчиком, присутствуют взаимовыручка и работа в команде. С нашей точки зрения, данные виды занятий, в отличие от пересказа, можно проводить и в группах до 20 человек, соблюдая регламент выступления.

Н. Г. Кондрахина в методических рекомендациях по проведению кейсов в подгруппах считает оптимальным количество 3-4 человека. Каждая подгруппа обсуждает и анализирует ситуацию, после чего вырабатывает свою точку зрения на проблему, генерирует различные идеи по поводу решения данной проблемы и затем оформляет решение в виде презентации / письменного отчета. «Решение и представление той или иной бизнес-ситуации (проблемы) может проходить и в индивидуальном формате, то есть как представление решения мини-кейса» $[5$, с. 54,55$]$. Не следует выбирать тексты с большим количеством терминов, так как снижается интерес студентов к заданию. Через две недели после проведения пересказа в форме мини-лекции, деловой игры и кейс-стади проводился промежуточный контроль, целью которого являлась проверка усвоения использованной тематической лексики и речевых клише. Он включал такие задания, как:

1) заполнение пропусков в предложении на английском языке тематической лексикой (The company wants to widen... the market share); 
2) перевод предложений с тематической лексикой и речевыми клише с русского на английский язык (Уважаемые коллеги, позвольте огласить повестку дня - Dear colleagues, let's announce the agenda of the meeting);

3) составление письменного высказывания на английском языке «Обращение к коллегам с предложением о продвижении товара». Количество правильно выполненных заданий составило 80\%, присутствовали орфографические и лексические недочеты типа "Please, give me your word" вместо give me the floor, let's collaborate вместо team up (20\%).

1. Легче запоминаются новые слова, т.к. сами придумываем текст, в составленных предложениях слова запоминаются легче, чем в заученных, возможность представить материал в форме презентации или видео.

2. Возможность попробовать себя в новой роли, тренируем ораторское мастерство, исчезает страх выступления на публике.

3. Не можем использовать переводчик, как при пересказе, т.к. самим приходится составлять предложения.

4. Групповая ответственность, более опытные сокурсники помогают с ответами.

— 5. Изучение иностранного языка должно быть разносторонним.

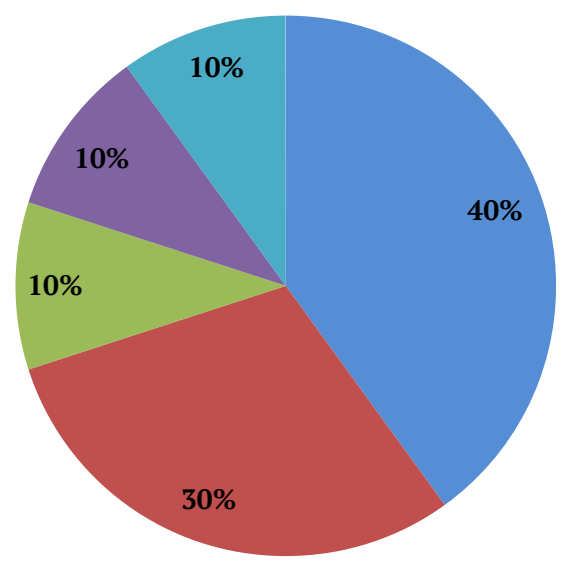

Рисунок 1. Преимущества деловой игры и кейс-стади

\section{1. Основная нагрузка и ответственность на 2 спикеров, следует давать всем больше возможностей высказаться. \\ 2. Значительное количество терминов в кейсах, сложность понимания.}

3. Не до конца ясна роль, выбор ролей не очень большой.

4. Боязнь сделать грамматическую
ошибку.

5. Трудно составлять текст к игре, при пересказе есть готовый образец.

6. Механически слова заучить проще.

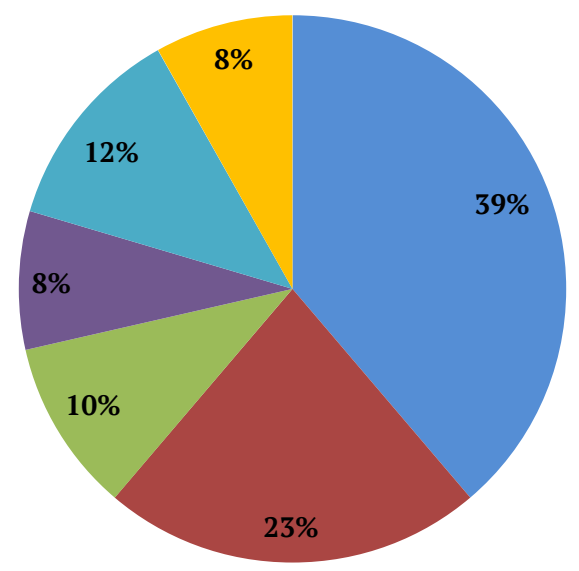

Рисунок 2. Недостатки деловой игры и кейс-стади

Итоговый контроль проводился через 2 месяца после проведения кейс-стади и деловой игры и включал такие задания, как:

1) перевод речевых клише с русского на английский язык (как выдвинуть идею, принять, отклонить), например: «Почему бы не сократить сроки поставки? Хорошо, давайте изменим девиз рекламной кампании. Нет, я бы не стал подписывать контракт»;

2) выбор англоязычного эквивалента в тесте, например: вести протокол: A. take a minute B. lead a protocol C. write a paper;

3) мини-сочинение на английском языке для проверки умений публичной речи: выступление на собрании (90\% правильно выполненных работ).

При выполнении перевода речевых клише с русского на английский язык высокий процент правильно выполненных работ (85\%). Затруднения возникли при выборе варианта перевода профессионально окрашенной лексики, например: lead a protocol вместо take a minute выбрали 80\% участников. 


\section{Заключение}

Проведенный экспериментальный анализ эффективности использования деловой игры, метода кейсстади и адресованного пересказа спецтекста на занятии по иностранному языку позволяет предложить следующие методические рекомендации.

1. Для контроля знаний содержания спецтекста и развития умений выступать публично у студентов рекомендуется использовать адресованный пересказ. Он является более привлекательной для студентов формой контроля по сравнению с неадресованным пересказом, но в меньшей степени развивает навыки работы в команде. Его предпочтительнее проводить «вживую», а не онлайн, для зрительного контакта с группой.

2. После адресованного пересказа, когда «багаж» тематической лексики и знания спецпредмета сформирован, рекомендуется проводить деловую игру и кейс-стади. Они являются оптимальными для подавляющего большинства студентов (70\%) методами обучения, так как формируют умение работы в команде, взаимовыручку, студенты развивают творческие способности в большей степени, чем при пересказе.

3. При высокой численности группы оптимально проводить одно занятие по иностранному языку с использованием метода кейс-стади и одно занятие с использованием деловой игры в течение семестра. Проведение мини-кейсов возможно онлайн, находит положительный отклик со стороны студентов.

4. Целесообразно сочетать, а не противопоставлять традиционные и инновационные методы обучения, такие как адресованный пересказ, кейс-стади и деловая игра. При условии систематического повторения и контроля учебного материала использование данных методов обучения способствует всестороннему развитию коммуникативной компетенции.

Исследование показало, что эффективность инновационных и традиционных методов обучения иностранному языку, таких как кейс-стади, деловая игра и пересказ, достигает 70-80\%. Инновационные и традиционные методы обучения не должны «конкурировать» и эффективны в сочетании: преимуществом адресованного пересказа является то, что он позволяет преподавателю лучше контролировать знание тематической лексики и содержание спецтекста у каждого студента по сравнению с занятием кейс-стади и деловой игрой, в то же время развивает у студентов умения публичной речи. У студентов занятия кейс-стади и деловая игра находят положительный отклик прежде всего потому, что они сами составляют текст и работают в команде (до 70\% респондентов). Качество запоминания лексики при этом зависит не от выбора метода обучения, а от систематического повторения. На практике выявлено, что мини-кейсы возможно проводить онлайн в группе до 20 человек, однако использование презентаций при этом ограниченно.

Положительные результаты исследования подтверждают научную новизну использования таких инновационных методов обучения, как деловая игра и кейс-стади, в том числе онлайн, в сочетании с традиционными методами обучения, в частности адресованным пересказом. Ценность результатов исследования заключается в том, что описанные в статье методические рекомендации могут использоваться в качестве эффективного педагогического приема в обучении профессиональному английскому языку в неязыковом вузе, поскольку вносят разнообразие и элемент новизны в учебный процесс, отвечая запросам современного студента и повышая его интерес к учебе, и помогают преподавателю выбрать оптимальное сочетание традиционных и инновационных методов обучения.

\section{Список источников}

1. Богиева Т. Р. Преимущества и недостатки применения традиционных и нетрадиционных методов преподавания иностранного языка в общеобразовательных учреждениях СПО // Инновационная наука. 2016. № 4. С. 139-142.

2. Войткова А. Н., Гончарова Т. В. Пересказ как основной когнитивный механизм формирования лингвокоммуникативной компетенции в профессиональном лингвообразовании // Филологические науки. Вопросы теории и практики. 2020. Т. 13. Вып. 5. С. 315-320. DOI: 10.30853/filnauki.2020.5.62.

3. Доронина М. В. Практикум ситуативных заданий для самостоятельной работы студентов первого курса. Дисциплина «Иностранный язык». М.: Финансовый университет, 2018. 110 с.

4. Киналь А. В., Комарова Е. В. Развитие умений говорения в процессе пересказа на практических занятиях по иностранному языку в вузе [Электронный ресурс]. URL: http://web.snauka.ru/issues/2015/04/51647 (дата обращения: 05.09.2020).

5. Кондрахина Н. Г., Звягинцева Е. П. Иностранный язык в профессиональной сфере: рабочая программа дисциплины. М.: Финансовый университет при Правительстве РФ, 2019. 71 с.

6. Кунгурова И. М., Воронина Е. В., Долженко С. Г. Арт-технологии в формировании инновационной педагогической деятельности у студентов [Электронный ресурc]. URL: https://naukovedenie.ru/PDF/ 31PVN614.pdf (дата обращения: 05.09.2020).

7. Лысенко Н. Е. Развитие приемов запоминания учебного материала при изучении русского и иностранного языков // Ученые записки Орловского государственного университета. 2011. № 6 (44). С. 412-419.

8. Маньковская 3. В. Английский язык для делового общения. Ролевые игры по менеджменту: учебное пособие. М.: Инфра-М, 2016. 118 с. 
9. Чуланова О. Л., Мухамедова М. М. Кейс-метод как эффективный инструмент в системе обучения управленческого персонала организации // Мир науки. 2015. Вып. 1. С. 1-13.

10. Шляхова В. А., Герасина О. Н., Герасина Ю. А. Английский язык для экономистов: учебник. М.: Дашков и К, 2014. $296 \mathrm{c}$.

11. Cotton D., Falvey D., Kent S. Market Leader. Business English Course Book. Edinburgh Gate - Harlow - Essex: Pearson Education, 2010. 176 p.

12. https://www.hbs.edu (дата обращения: 15.09.2020).

\section{Информация об авторах | Author information}

RU Лысенко Наталья Евгеньевна ${ }^{1}$, к. пед. н.

${ }^{1}$ Орловский государственный аграрный университет имени Н. В. Парахина

EN Lysenko Nataliya Evgenievna ${ }^{1}, \mathrm{PhD}$

${ }^{1}$ Orel State Agrarian University named after N. V. Parakhin

${ }^{1}$ n.lysenko@inbox.ru

\section{Информация о статье | About this article}

Дата поступления рукописи (received): 11.08.2020; опубликовано (published): 30.10.2020.

Ключевые слова (keywords): экспериментальный анализ; деловая игра; метод кейс-стади; неязыковой вуз; пересказ; experimental analysis; business game; case study method; non-linguistic higher school; rendering. 